
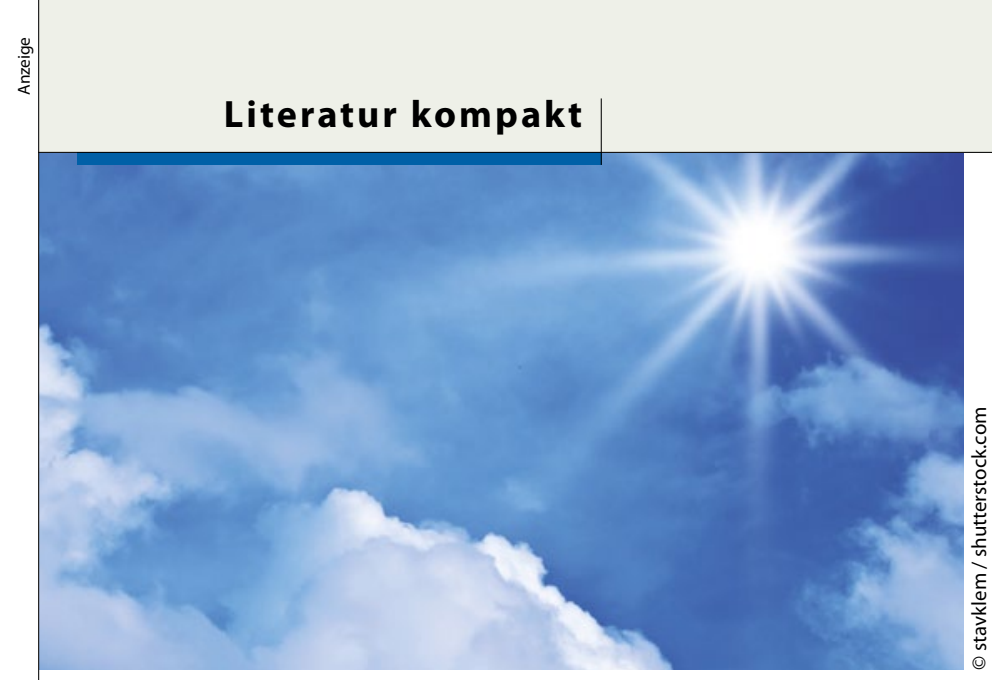

\title{
Sonne schadet der Kinderhaut nicht nur im Urlaub
}

Die meisten Eltern sind gut darüber informiert, welche Hautschäden durch Sonne entstehen und wie sie ihre Kinder vor der UV-Strahlung schützen können. Sie setzen diese Kenntnis aber meist nur im Urlaub um und nicht zu Hause.

— in Viertel bis zur Hälfte der lebenslangen UV-Belastung fällt in — die Zeit vor dem 21. Lebensjahr. Dabei erreicht die jährliche UV-Dosis eines Kindes etwa das Dreifache der Dosis von Erwachsenen. Schon deshalb sind Kinder eine besonders wichtige Zielgruppe für die Prävention von Hautkrebs. Wie es um den Sonnenschutz im Kindergartenalter steht, untersuchten Forscher der Universität Erlangen. Insgesamt 2.619 Familien beantworteten Fragen zum Thema Hautkrebsrisiko. Zusätzlich machten sie Angaben darüber, mit welchen Maßnahmen sie ihre Kinder am Strand und im Garten vor der Sonne schützen.

Die Antworten ergaben, dass 41\% der Eltern zu diesem Thema sehr gut informiert waren, $37 \%$ hatten einen mittleren Kenntnisstand und $22 \%$ wussten wenig über die Gefahren des UV-Lichts. Je besser die Eltern über die Risiken informiert waren, desto mehr effektive Maßnahmen ergriffen sie zum Schutz ihrer Kinder - allerdings nur im Urlaub. Die Gefahren zu Hause schätzten viele - unabhängig von ihrem Kenntnisstand - offenbar als relativ gering ein.

Sowohl im Garten als auch am Meer spielte beispielsweise jedes zweite Kind meist im Schatten. Während am Strand 90,9\% üblicherweise einen Sonnenhut auf dem Kopf hatten, waren es im heimischen Garten nur 74,3\%. T-Shirt und Shorts trugen im Garten 84,6\%, am Strand $29,7 \%$.

Kinder, die im Garten spielten, wurden überwiegend nur einmal täglich eingecremt (59,3\%), 11,4\% selten oder gar nicht. Nur bei 29,3\% wurde der Sonnenschutz auf der Haut alle zwei bis drei Stunden erneuert, am Strand dagegen bei 79,2\% der Kinder.

Fazit: Die Autoren geben zu bedenken, dass Kinder insgesamt deutlich mehr Zeit zu Hause im Freien verbringen als in einem kurzen Urlaub am Strand. Da die Summe der UV-Expositionen die Entwicklung von Melanomen und anderen Hauttumoren fördert, ist verstärkte Aufklärung nötig, damit Eltern auch die heimische Situation richtig einschätzen und ihre Kinder schützen.

Dr. Christine Starostzik

Li J. et al. A comparison of patterns of sun protection during beach holidays and everyday outdoor activities in a population sample of young German children. Br J Dermatol 2012; 166: 803-10 